\begin{tabular}{|l|l|l|l|l|l|}
\hline Revista Jangwa Pana & ISSN: 1657-4923 & Vol. 15 & No. 1 & 28 - 42 & Enero - Junio de 2016 \\
\hline
\end{tabular}

DOI: http://dx.doi.org/10.21676/16574923.1747

\title{
TENDENCIAS ORGANIZATIVAS Y TIPOS DE PODER EN DOCE LÍDERES DEL MUNICIPIO DE SAN GIL, SANTANDER
}

\section{ORGANIZATIVE TRENDS AND TYPES OF POWER OF TWELVE LEADERS IN THE MUNICIPALITY OF SAN GIL, SANTANDER}

\author{
Wilmer A. Hernández-Velandia ${ }^{1}$
}

\begin{abstract}
RESUMEN
El presente artículo da a conocer los resultados de la investigación basada en la recuperación etnográfica de los discursos de doce líderes sociales, culturales y de partidos políticos en el municipio de San Gil, Santander, en el marco de las Elecciones Legislativas de 2010 en Colombia. Se logran distinguir dos propuestas así: se identifican dos tendencias organizativas, una partidista y otra de autonomía social, cada una con interpretaciones distintas sobre problemas, propuestas de solución, roles y conceptos base; de otro lado, se deducen dos tipos de poder, uno representativo y otro diversificante, explicando la manera como éstos se fortalecen o debilitan en una u otra tendencia organizativa.
\end{abstract}

Palabras clave: Democracia; discurso; poder; representación; autonomía social; San Gil

\section{ABSTRACT}

This article presents the results of an ethnographic research where twelve discourses of cultural, political party and social leaders of the municipality of San Gil were collected, in the run-up to the Legislative Elections of 2010 in Colombia. Thus, it distinguishes two proposals: it identifies two organizational trends, the partisan and the social autonomy, each having different interpretations of local problems, proposed solutions, identified social roles and key concepts. On the other hand, it deducts two types of power, representative and diversifying, explaining how they strengthen or weaken in either organizational trend.

Keywords: Democracy; discourse; power; representation; social autonomy; San Gil

Tipología: Artículo de investigación científica y tecnológica

Fecha de recepción: 20/08/2015

Fecha de aceptación: 10/03/2016

Como citar este artículo: Hernández, W. (2016). Tendencias organizativas y tipos de poder en doce líderes del municipio de San Gil, Santander. Jangwa Pana, 15 (1), 28 - 42 


\section{INTRODUCCIÓN}

$\mathrm{C}$ on la apertura de la antropología al estudio de otros grupos humanos no necesariamente aisladas de las sociedades de Europa y Estados Unidos y el reconocimiento pleno desde los años de 1960 de una antropología capaz de indagar no solo sobre fragmentos marginados e incluso estigmatizados de estas mismas sociedades (Guber, 2001), sino además capaz de exotizar el contexto más familiar del investigador, el propio y hacer incluso etnografía de la ciudades o en la ciudades (Salcedo \& Zeiderman, 2008), se hace posible el uso del método etnográfico desde otras disciplinas, para el estudio de agrupación humanas de cualquier tipo o lugar.

De otro lado, como apunta Guber (2001), a propósito de los presupuestos de la etnometodología, alternativa desde la crítica posestructuralista a la metodología cuantitativa y positivista en los estudios sociales (Apud, 2013),

\section{[...], el vehículo por excelencia de} reproducción de la sociedad es el lenguaje. Al comunicarse entre sí la gente informa sobre el contexto, y lo define al momento de reportarlo; esto es, lejos de ser un mero telón de fondo o un marco de referencia sobre lo que ocurre "ahí afuera", el lenguaje "hace" la situación de interacción y define el marco que le da sentido. Desde esta perspectiva, entonces, describir una situación, un hecho, etc., es producir el orden social [...]. (Guber, 2001, p.17)

Tomando estos y otros referentes, ha tenido lugar una investigación basada en la recuperación etnográfica de los discursos de doce líderes sociales, culturales y de partidos políticos en el municipio de San Gil, Santander, en el marco de las Elecciones Legislativas de 2010 en Colombia. Los principales puntos de dicha investigación son expuestos en el presente artículo, el cual re- cupera sus fundamentos teóricos, la metodología y las técnicas utilizadas, el proceso de elaboración de hipótesis y los principales resultados.

En un tiempo y lugar donde es frecuente el uso de conceptos como democracia, descentralización, participación ciudadana, territorialidad, Constitución Política, entre otros, es necesario desplegar con más frecuencia investigaciones que muestren la manera como dichos conceptos son acogidos y producidos a nivel local. Si en un Estado se han planteado unos objetivos constitucionales basados en dichos criterios, resulta imprescindible preguntar por aquello que se entiende cuando se nombran: ¿Quiénes están dando una explicación?, ¿a través de qué canales los ciudadanos tienen noticia de ellos?, ¿qué aspectos específicos están siendo recuperados y qué otros desechados?, ¿quiénes se benefician de esta manera y quiénes se perjudican?

Puede apelarse al derecho al voto como prueba de que la ciudadanía ya no se encuentra aislada de los asuntos públicos locales y nacionales. Sin embargo, como se podrá observar, a través del análisis del discurso de distintos líderes en busca de propuestas organizativas, estrategias de persuasión y del uso que hacen de las fuentes que los acredita ante la sociedad como candidatos idóneos para ejercer cargos públicos, o bien, para tener cierta actuación política o influencia social se encuentran elementos que debilitan esta prueba.

En el decurso de la investigación se logran abstraer dos propuestas desde los distintos discursos recuperados: Se identifican dos tendencias organizativas, una partidista y otra de autonomía social, cada una con interpretaciones distintas sobre problemas, propuestas de solución, roles y conceptos base; de otro lado, se deducen dos tipos de poder, uno representativo y otro diversificante, explicando la manera como éstos se fortalecen o debilitan en una $\mathrm{u}$ otra tendencia organizativa. Por otra parte, entre las principales conclusiones resultantes se encuentran: a) el sufragio es susceptible de convertirse en un meca- 
nismo que deja por fuera del escenario político a quien deseaba participar en los asuntos públicos de esta manera; b) no ha cambiado la relación patrón-cliente, se han invertido estratégicamente estos roles en el discurso de los candidatos; c) el clientelismo va más allá de la relación políticocliente y se extiende al interior de los partidos; d) la oposición entre partidos es más pragmática que ideológica; e) el candidato no es elegido por la idoneidad de su proyecto, sino a causa de su aparente origen popular o local, su capacidad diplomática para gestionar y el respaldo de una red partidista eficiente; f) los tiempos de campaña electoral, para los líderes partidistas, son una oportunidad más de afianzar roles prescritos para todos los miembros de una sociedad y no de cambios organizativos.

\section{Organizaciones, redes e instituciones}

El concepto de organización no implica en esta investigación una descripción sobre el modo de ordenamiento, que de hecho se puede observar en una localidad. Ese no es el objetivo, es lo que los líderes tienen por decir al respecto. No se creyó necesario, en principio, una teoría elaborada sobre este concepto, dado que uno de los propósitos es encontrar datos relevantes en el discurso de los líderes que orientaran posteriormente unas tendencias organizativas, por ello es suficiente con suponer que el concepto de organización implica elementos tanto culturales como estructurales, es decir, valores y normas de comportamiento específicos, pero además, instituciones, funciones, relaciones y jerarquías; al respecto la definición de Rocher (1990), ha permitido estar alerta a cualquier propuesta organizativa: Reticular, institucional, híbrida. Esto significa que al hablar de organizaciones, la investigación no sólo se refirió a una estructura jerárquica con roles y objetivos definido; no obstante, ya desde el análisis etnográfico y argumentativo del primer discurso, se encuentra que de alguna manera la propuesta clientelar que ofrecía el líder parecía más una red que un siste- ma institucional con objetivos y metas claros. Y a pesar de que "cuerpo organizado" se oponga a "cuerpo sin órganos" (Deleuze \& Guattari, 1994, p.6), o de qué organización se oponga a esta red, en todo caso no se ha encontrado un consenso en las investigaciones sociales de este tipo acerca de un concepto neutro para referirse a todas estas formas organizativas.

En la práctica, a causa de ello, hubo indecisión sobre la manera cómo, por ejemplo, había que referirse a las relaciones clientelares, que fue una de las propuestas organizativas encontradas. Como encuentra Rivoir (1999), quienes usan el concepto de red en estudios sociales normalmente desean recuperar las propiedades de horizontalidad y descentralización existentes en una relación de partes o todos heterogéneos, sin embargo, una relación de tipo reticular también implica una gran capacidad de conexión y desconexión entre estos y nuevos componentes (Lins, 2007; Bauman, 2005).

Se pensó también en llamar a dicha relación organización o institución, incluso burocracia; pero estas nociones implican necesariamente una estructura definida con propósitos concretos y funciones bien reguladas (Deleuze \& Guattari, 1994), todo lo contrario a una red. Ahora bien, a pesar de que los partidos políticos operen como una institución u organización, eso no evita que tengan interés en aliarse o buscar conexiones con entes externos, lo cual sólo se logra si poseen cierta flexibilidad reticular. Esto permite suponer que los conceptos de organización o de red, o bien, son en cierto sentido limitados para explicar la dinámica de este tipo de relación, o bien, es difícil encontrarlos en estado puro; por ello es lícito pensar sólo en tendencias. Así, puede decirse que existen formas relacionales que tienden a la institucionalización y jerarquías conservando propiedades reticulares como estrategia de alianza; y de tipo reticulares que adelantan procesos básicos de institucionalidad, según lo encontrado en la investigación. 


\section{MATERIALES Y MÉTODOS}

Dichas tendencias organizativas se han construido recuperando las propuestas de doce líderes en el municipio de San Gil, Santander; para ello se han atendido a las fuentes más evidentes de poder: Líderes políticos, sociales, académicos y artístico-culturales; quienes sobresalen por sus frecuentes expresiones en público con un mensaje de cambio, reforma o afirmación, ya que esto, unido a las facultades de persuasión, cohesión y coerción que pueden tener y los recursos o medios de los que disponen (Dijk, 2004), los convierte en agentes capaces de modelar las acciones de los individuos. El marco para algunas de estas propuestas es la época de campaña para las Elecciones Legislativas del 14 de marzo de 2010 en Colombia; otras, corresponden a discursos de líderes influyentes que no necesariamente pertenecen a algún partido político. Las propuestas se obtienen a través de su captura en audio o video en lugares públicos y aplicando entrevistas semiestructuradas, siguiendo, en la medida de lo posible, el método etnográfico para el rastreo de datos (Guber, 2001), el cual ha permitido obtener las categorías sobre política y sociedad relevantes con cada líder; su significado y su valor específico, teniendo cuidado de no confundirlas con representaciones sociales y puntos de vista propios.

El análisis de los datos obtenidos apuntó a una descripción del escenario, de las formas argumentativas, los mensajes implícitos (Jiménez, 2005, p.156), las falacias utilizadas y de los afectos y valores evocados, así como de la valoración y estructuración que hace cada líder de los distintos sectores de la sociedad. Al mismo tiempo, se fueron estableciendo puntos de comparación entre las distintas propuestas en busca de lugares comunes y diferencias radicales, sin embargo, estos puntos de comparación son abstracciones de los mismos discursos a causa de su recurrencia, lo cual se realiza con el objeto de no hacer de la investigación un molde donde se introducen unos datos disponibles.

\section{El discurso}

Las emisiones de los líderes se han tomado como discursos, en la acepción más básica a la que hace referencia Dijk (1996): "emisión discursiva, como ocurrencia", como "un evento empírico inmediato en un contexto particular y único" (p.20), es decir, no como abstracción sometida al análisis semántico o sintáctico, sin embargo, el hecho de que se tome para esta investigación como unidad de análisis al discurso demuestra la importancia que se otorga a la palabra como acto de habla, que contiene una intención y, con ello, una función específica encaminada a la satisfacción de alguna necesidad, procurando, a través del ejercicio argumentativo y retórico para la persuasión y la adhesión de un auditorio, la apropiación de los símbolos sociales y el fortalecimiento o eventual cambio de las estructuras sociopolíticas y, con ello, las preferencias del auditorio y su identidad (Dijk, 1996; Ramírez, 2005; Botero, 2005).

\section{El poder}

Clastres (1978) distingue entre poder coercitivo y poder no coercitivo. El que haya encontrado en las "sociedades arcaicas", como él las llama, ejemplos de jefes sin autoridad, no significa que no tuvieran una organización política y menos que se hallaran en estado de anarquía, como lo creían la etnología y la filosofía política en sus comienzos (Clastres, 1978). En otras palabras, que no se dé en una agrupación étnica un tipo de poder coercitivo, jerárquico y centralizado, no significa que no tengan poder político alguno, pues éste no es el único, tan sólo el propio de la sociedad estatal moderna.

Al respecto, los estudios de Janet Hendricks (1996) pueden indicar la posibilidad de una interpretación un tanto ideal por parte de Clastres con respecto a su tipología. Ya que, si bien, pueden observarse distintos tipos de poder entre algunas agrupaciones indígenas, estos no son completamente opuestos. Hendricks ha encontrado entre 
los indígenas shuar, sociedad indígena amazónica del sureste ecuatoriano, que el uso de la palabra, la oratoria, la habilidad para convencer y solucionar conflictos interpersonales y la generosidad, características todas del tipo de poder no coercitivo, pueden ir perfectamente acompañadas de gran habilidad y fuerza física; es más, éstas últimas parecen ser condiciones que legitiman una posición de autoridad para la cual habrá un respaldo social.

Asimismo, Auyero (2008), siguiendo a Bourdieu, ha logrado en sus investigaciones, sin mencionarlo, dar pruebas de la falta de universalidad de la dualidad que propone Clastres. Observando las "visiones diferentes que los clientes tienen de la política clientelar" (p.6), en una villa muy pobre, ubicada en la ciudad de Cóspito, Argentina, al sur de Buenos Aires, Auyero ha encontrado que los líderes perteneciente a un partido político con grandes recursos, pueden perfectamente ser percibidos por la comunidad como líderes que implementan un tipo de poder no coercitivo, es decir, que aparecen a los ojos de la comunidad como desprendidos de los bienes materiales, dispuestos en todo momento a solucionarle los problemas a todo el mundo y a sacrificarse por los demás. A cambio de ello, la comunidad respalda en agradecimiento con su presencia y voto a dichos líderes. De este modo, el poder sigue de parte del líder partidista, con pleno consentimiento de una comunidad que se mantiene frágil; en otras palabras, pueden combinarse las dos formas de poder haciendo mucho más complejas las relaciones, los afectos y los significados sociales. Las anteriores explicaciones de Hendricks y Auyero empatan muy bien con la opinión de Dijk (2004), quien distingue entre "poder coercitivo" y "poder discursivo". El primero, según él, es poder físico ejercido directamente sobre los cuerpos, como el de las milicias, la policía y, a nivel privado, del poder coercitivo que ejercería el hombre sobre el cuerpo de la mujer (Rodríguez, Padilla, Rodríguez, \& Díaz, 2010). Exactamente lo que para Foucault (2001) es violencia y lo que en definitiva no es poder, según él.
Del poder discursivo Dijk afirma que es mental, encaminado a controlar las acciones de los individuos, las cuales deben ejecutar desde su "libre albedrío o bien porque no tienen alternativa" (Dijk, 2004, p.9), tal vez porque no cuentan con acceso, por ejemplo, a otras fuentes de información alternas a las dispuestas por el poder que intenta orientar su conducta.

Al respecto, y siguiendo las indicaciones de Benjamin (1998), pero también las de otros autores mencionados con anterioridad, para la presente investigación no se consideró conveniente separar violencia y poder, pues además de seguir siendo un método efectivo para la adhesión de alguien a los intereses de otro, junto con los dispositivos conceptuales implementados a través de un discurso, aquella puede desplegarse perfectamente desde lo jurídico, pues toda ley es violenta en la medida que es decretada por quien ha salido vencedor de una confrontación, por quien ha podido derrotar a otro y ahora intenta normalizar o acoplar a los vencidos a sus dinámicas sociales y conductuales (Benjamin, 1998). El poder siempre puede usar la violencia, y puede no ser conveniente, para los objetivos de la presente investigación al menos, distinguirla de las acciones refinadas propias del poder foucaultiano, porque la precondición pura que debe existir para que sea posible una relación de poder, esto es, la libertad plena de los individuos, aún es cuestionable (la falta de alternativas de Dijk). Todo individuo es social y está condicionado de antemano por algún tipo de reglamentación moral y ética impuesta.

Por ello, los tipos de poder anteriormente descritos, aun cuando han aportado datos y un mapa general de rastreo entre los distintos discursos, no permiten una completa comprensión de los poderes encontrados en el análisis. Lo coercitivo, lo discursivo o lo no coercitivo han resultado ser apenas medios que incluso pueden ser utilizados al tiempo y por lo cual no pueden definir el poder. Llamar a uno o a otro poder coercitivo o consensual no explica la forma como se conserva, 
despliega o fortalece; por el contrario, al llamar a uno de ellos representativo y al otro diversificante, como veremos en la tercera parte, tratamos de recuperar precisamente su modo de ser en la sociedad: la manera como han podido o podrían conservarse, expandirse y fortalecerse.

\section{El municipio}

Se ha tomado a San Gil como un municipio entre muchos otros. Describir en detalle el contexto no aporta datos contundentes en esta oportunidad, donde se ha privilegiado el uso de la palabra. A pesar de la manera subjetiva como cada cual pueda sentir una situación o un ambiente, no está de más ofrecer, al menos, un par de datos cuantitativos que permitan dimensionar el lugar y limitar los afectos. De este modo se puede decir que San Gil es un municipio ubicado en la parte sur del Departamento de Santander, a 96 kilómetros de su capital, Bucaramanga y a 327 de Bogotá D.C. y su temperatura media es de $24^{\circ}$ (Alcaldía de San Gil, 2008).

Santander se encuentra dividido en seis provincias (Soto, Guanentá, Comunera, Vélez, Mares y García Rovira) y le atraviesa de norte a sur la Cordillera Oriental. A ello se deben sus carreteras sinuosas, discontinuas, inclinadas, acompañadas en ocasiones por abismos y por enormes columnas de piedra erosiva.

San Gil se encuentra partido en dos por el Rio Fonce, y sus calles llegan a alcanzar una inclinación de hasta $40^{\circ}$ (Comunicación personal desde la oficina de Planeación de San Gil). Las estadísticas señalan que en el 2007 San Gil contaba con una población de 43.928 habitantes, de la cual 37.876 se encontraba en la cabecera municipal y 6.052 en la zona rural (Gobernación de Santander, 2008). En la actualidad San Gil es la capital de la Provincia de Guanentá o Guanentina; nombre que recuerda los indígenas guanes, de quienes sólo quedan historias populares de lucha, persecución, muerte y suicidio y restos humanos, pictogramas y petroglifos de interés arqueológico.

\section{Los líderes}

La investigación privilegió el discurso de doce líderes, quienes no son los únicos con capacidad e instrumentos suficientes para intervenir y generar cambios a nivel social. En un período de tiempo dado, finales de 2009 y mediados de 2010 , estos son los que se han alcanzado a reconocer como tales y de quienes se ha podido recoger datos. El método de análisis ha consistido en el rastreo etnográfico de elementos argumentativos y retóricos que han servido a los líderes en su deseo de convencer. La etnografía ha intentado cumplir con los siguientes objetivos en su desarrollo: a) Sustraer una síntesis sobre la propuesta hecha en cada discurso y b) compararlas todas entre sí. Para ello se ha puesto la atención en a) la búsqueda de temas y categorías en común o radicalmente opuestas que van apareciendo en la comparación de los distintos discursos y en b) el rastreo de falacias y de la intención de la argumentación usada y su debilidad en cada caso.

Se han privilegiado de este modo, en primer lugar, los discursos pronunciados en lugares públicos de los siguientes ocho líderes:

- Honorio Galvis y Jorge Gómez Villamizar, candidatos a la Cámara y al Senado de la República por el Partido Liberal

- Carlina Rodríguez y Didier Tavera, candidatos al Senado y a la Cámara por el Partido Conservador Colombiano y el Partido de Integración Nacional, PIN

- Mario Suárez y Jaime Durán, candidatos a la Cámara y al Senado por el Partido Liberal

- Rafael Serrano, director del Partido Conservador Colombiano en Santander

- Hugo Eliodoro Aguilar, ex-gobernador del Departamento de Santander.

Y cuatro discursos más obtenidos a través de entrevistas personales con:

- Jesús Villar, ex-concejal y precandidato a la alcaldía de San Gil 
- Manuel Sánchez, maestro de Bellas Artes

- Miguel Fajardo, coordinador regional de la Misión de Observación Electoral, MOE

- Fernando Tibaduiza, Gerente de la Red Cooperativa de Medios de Comunicación Comunitarios de Santander, RESANDER.

Ha sido posible sintetizar las doce propuestas en sólo unas cuantas, dada la similitud de sus estrategias de convencimiento y sus ofertas de organización sociopolítica. Algunas de las categorías que se tuvieron en cuenta coinciden con el esquema narrativo utilizado comúnmente en estudios semiológicos. Éste es el caso de los resultados encontrados por Richard (2009), a propósito de la campaña electoral del entonces candidato a la presidencia de la República Álvaro Uribe. Se retoma el mismo esquema narrativo con el fin de obtener un mejor reconocimiento de las propuestas de cada líder, ya que en el presente artículo nos es imposible dar a conocer el pleno del tra- bajo etnográfico. El interés de la construcción de dicho esquema narrativo a través de una tabla (Tabla 1), de la cual solo se ofrece un fragmento aquí, no es afirmar una causalidad. No se intenta defender un orden estricto de las circunstancias expuestas por los líderes, pues cada posibilidad da para una discusión. Por ejemplo, no se verifica si un sistema autoritario da lugar a una democracia representativa, o si es la implantación de una democracia representativa la que da lugar a sistemas autoritarios. El objetivo de la tabla de narrativas es capturar los datos más relevantes sobre organización sociopolítica y desligarlos de otro tipo de información que tiene que ver con estrategias de convencimiento y adquisición de votos. De otro lado, no todos los líderes mantienen un discurso acorde a un esquema narrativo compuesto por un supuesto héroe, un villano, un inicio espléndido, un nudo problemático y un final feliz. No obstante, se reitera, el cuadro permite tener una mejor visualización de los datos relevantes disponibles.

Tabla 1. Fragmento de las tablas narrativas construidas para el discurso de cada uno de los líder objeto de estudio en la presente investigación.

\begin{tabular}{|c|c|c|c|c|c|c|c|}
\hline 章 & Situación inicial & $\begin{array}{c}\text { Elementos } \\
\text { perturbadores }\end{array}$ & Crisis & Aparición del héroe & Peripecias & $\begin{array}{l}\text { Restablecimiento } \\
\text { de la situación } \\
\text { inicial }\end{array}$ & Recompensa \\
\hline 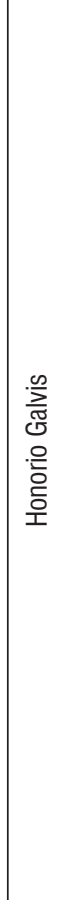 & $\begin{array}{l}\text { (Al parecer, los } \\
\text { estratos bajos } \\
\text { de la sociedad } \\
\text { gozan de cali- } \\
\text { dad de vida y } \\
\text { posibilidades } \\
\text { de ascenso.) }\end{array}$ & $\begin{array}{l}\text {-La llegada del } \\
\text { presidente Uribe } \\
\text { al poder cen- } \\
\text { tral y la gestión } \\
\text { de los partidos } \\
\text { uribistas. } \\
\text {-Los turistas de } \\
\text { "mochila" de ba- } \\
\text { jos recursos. }\end{array}$ & $\begin{array}{l}\text {-Injusticia so- } \\
\text { cial, donde la } \\
\text { ciudadanía de } \\
\text { bajos recurso } \\
\text { sale gravemente } \\
\text { afectadas; y la } \\
\text { de altos ingre- } \\
\text { sos, junto con } \\
\text { los integrantes } \\
\text { de los partidos } \\
\text { políticos, salen } \\
\text { beneficiadas. } \\
\text {-Los turistas } \\
\text { de "mochila" } \\
\text { y "carpa" no } \\
\text { dejan buenas } \\
\text { ganancias y sí } \\
\text { son un riesgo } \\
\text { económico y } \\
\text { ecológico para } \\
\text { el municipio. }\end{array}$ & $\begin{array}{l}\text {-Porvenir: el Partido } \\
\text { Liberal promete ha- } \\
\text { cer una distribución } \\
\text { justa y equitativa de } \\
\text { los recursos públi- } \\
\text { cos y dotar a San Gil } \\
\text { de la infraestructura } \\
\text { adecuada para la } \\
\text { acogida de turistas } \\
\text { con alta capacidad } \\
\text { adquisitiva. }\end{array}$ & $\begin{array}{l}\text { Porvenir: El Partido } \\
\text { Liberal derrotará en } \\
\text { las elecciones al } \\
\text { Senado y la Cámara } \\
\text { a los partidos uribis- } \\
\text { tas y se impondrá } \\
\text { mayoritariamente en } \\
\text { el Parlamento. } \\
\text {-Porvenir: Rafael } \\
\text { Pardo derrotará a los } \\
\text { candidatos uribistas } \\
\text { en las elecciones a } \\
\text { la Presidencia de la } \\
\text { República y se hará } \\
\text { al poder central. } \\
\text {-Porvenir: La red } \\
\text { partidista que se } \\
\text { extiende desde el } \\
\text { poder central hasta } \\
\text { el regional y provin- } \\
\text { cial se fortalece y } \\
\text { fluyen mayores re- } \\
\text { cursos económicos } \\
\text { al Departamento. } \\
\text {-Se estigmatiza a los } \\
\text { otros partidos y a } \\
\text { sus miembros. }\end{array}$ & $\begin{array}{l}\text { Porvenir: Los es- } \\
\text { tratos bajos me- } \\
\text { joran su calidad } \\
\text { de vida y el me- } \\
\text { dio ambiente se } \\
\text { recupera. }\end{array}$ & $\begin{array}{l}\text {-Porvenir: Mantenimiento } \\
\text { y Reconocimiento legíti- } \\
\text { mo por parte de la ciuda- } \\
\text { danía, del Partido Liberal } \\
\text { como la primera fuerza } \\
\text { política del país. }\end{array}$ \\
\hline
\end{tabular}




\section{Continuación Tabla 1.}

\begin{tabular}{|c|c|c|c|c|c|c|c|}
\hline 흠 & Situación inicial & $\begin{array}{c}\text { Elementos } \\
\text { perturbadores }\end{array}$ & Crisis & Aparición del héroe & Peripecias & $\begin{array}{l}\text { Restablecimiento } \\
\text { de la situación } \\
\text { inicial }\end{array}$ & Recompensa \\
\hline 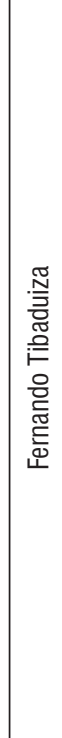 & $\begin{array}{l}\text {-En Santander, } \\
\text { y en especial } \\
\text { en San Gil, } \\
\text { las empresas } \\
\text { cooperativas } \\
\text { son prosperas } \\
\text { y se encuentra } \\
\text { fuerte el ideal } \\
\text { de mantener } \\
\text { un equilibrio } \\
\text { entre bienestar } \\
\text { social, protec- } \\
\text { ción del me- } \\
\text { dio ambiente } \\
\text { y desarrollo } \\
\text { económico. }\end{array}$ & $\begin{array}{l}\text {-Las empresas } \\
\text { capitalistas prio- } \\
\text { rizan el desarro- } \\
\text { llo economicista } \\
\text { a costa del bien- } \\
\text { estar social y del } \\
\text { medioambiente. } \\
\text {-Los últimos } \\
\text { g o b i e r n o s } \\
\text { des e stimulan } \\
\text { la creación } \\
\text { de empresas } \\
\text { solidarias. }\end{array}$ & $\begin{array}{l}\text {-Inequidad e in- } \\
\text { justicia social. } \\
\text {-Deterioro y } \\
\text { disponibilidad } \\
\text { baja de recursos } \\
\text { naturales. } \\
\text {-No se crean } \\
\text { nuevas empre- } \\
\text { sas solidarias y } \\
\text { las que existen } \\
\text { tienen cada vez } \\
\text { más dificulta- } \\
\text { des para con- } \\
\text { solidarse en el } \\
\text { mercado. }\end{array}$ & $\begin{array}{l}\text {-Los líderes del sec- } \\
\text { tor solidario (emiso- } \\
\text { ras y asociaciones } \\
\text { comunitarias, cen- } \\
\text { tros cooperativos de } \\
\text { educación, sector } \\
\text { financiero solidario) } \\
\text { se han unido en bus- } \\
\text { ca de estrategias de } \\
\text { desarrollo humano } \\
\text { integral. }\end{array}$ & $\begin{array}{l}\text {-Desarrollo de la } \\
\text { comunicación co- } \\
\text { munitaria, a partir y } \\
\text { para la participación } \\
\text { ciudadana } \\
\text {-El desarrollo de li- } \\
\text { derazgos, a partir } \\
\text { y para el desarrollo } \\
\text { así mismo de una } \\
\text { educación basa- } \\
\text { da en principios } \\
\text { cooperativos. } \\
\text {-Generación de figu- } \\
\text { ras políticas repre- } \\
\text { sentativas desde el } \\
\text { seno de la ideología } \\
\text { cooperativa. } \\
\text {-Creación de políti- } \\
\text { cas públicas de apo- } \\
\text { yo al sector solidario. } \\
\text {-Crecimiento del } \\
\text { sector solidario. }\end{array}$ & $\begin{array}{l}\text {-El sector solida- } \\
\text { rio es nuevamente } \\
\text { fuerte y consolida- } \\
\text { do en la región. }\end{array}$ & $\begin{array}{l}\text {-Equidad y justicia social } \\
\text {-Medio ambiente protegi- } \\
\text { do y recursos naturales } \\
\text { disponibles. }\end{array}$ \\
\hline
\end{tabular}

Fuente: Elaboración propia.

\section{RESULTADOS}

La sistematización (Tabla 2) y el análisis de la información recolectada (relacionamiento con fuente secundaria) ha permitido la elaboración de cuadros comparativos desde los cuales pueden definirse tendencias organizativas y tipos de poder, temas en común y el desarrollo o interpretación que cada tendencia hace de algunos conceptos.

Tabla 2. Tendencias organizativas de las dos propuestas reconstruidas

\begin{tabular}{|c|c|}
\hline \multicolumn{2}{|c|}{ TENDENCIAS ORGANIZATIVAS } \\
\hline PROPUESTAS PARTIDISTAS & PROPUESTAS DE AUTONOMÍA SOCIAL \\
\hline $\begin{array}{l}\text {-Democracia: Representativa, donde los partidos políticos } \\
\text { son los únicos canales de comunicación con el Estado y de } \\
\text { distribución de recursos públicos. } \\
\text {-Participación ciudadana: Se limita al voto. Es el problema y, } \\
\text { por ello, el objeto a intervenir. La sociedad no puede ser pro- } \\
\text { positiva, sólo es receptora de acciones de líderes de partido, } \\
\text { no actúa. } \\
\text {-Partidos políticos: se encuentran compuestos por hom- } \\
\text { bres superiores. Establecen los términos de la relación líder- } \\
\text { sociedad, interpretan unilateralmente la situación social y los } \\
\text { criterios de análisis de sus propias propuestas. } \\
\text {-Constitución Políticas de } 1991 \text { como fuente de legitima- } \\
\text { ción: Reducción de ella al derecho al voto. }\end{array}$ & $\begin{array}{l}\text {-Democracia: Donde las ciudadanías tienen alternativas de } \\
\text { negociación directa con el Estado, sin intermediarios y donde } \\
\text { pueden postular representantes pertenecientes a agrupacio- } \\
\text { nes humanas específicas. } \\
\text {-Participación ciudadana: Son parte de los problemas de un } \\
\text { país, pero de donde deben surgir las propuestas de solución } \\
\text { y las acciones correspondientes. Las responsabilidades no } \\
\text { se delegan. } \\
\text {-Partidos políticos: Son parte del problema también, pero no } \\
\text { se trata de intervenirlos. La acción política ciudadana no les } \\
\text { debe dejar más alternativa que apoyar sus propuestas. } \\
\text { Constitución Política de } 1991 \text { como fuente de legitima- } \\
\text { ción: Recuperación de otras formas de participación política } \\
\text { ciudadana }\end{array}$ \\
\hline
\end{tabular}

Fuente: Elaboración propia. 
Como se observa, pueden compararse punto por punto las definiciones que cada una de las propuestas han hecho de temas en común. Al parecer se trata de dos proyectos sociopolíticos completamente distintos, a pesar de que ambos apelan a los mismos símbolos verbales que ya han sido aceptados por un auditorio.

De otro lado, la tesis nietzscheana -según la cual toda voluntad de poder tiende a organizar su entorno de tal manera que pueda encontrar las condiciones idóneas para su despliegue y fortalecimiento- permite comprender dichas tendencias organizativas -y al pensamiento que las establececomo formas de vida (Nietzsche, 2002, p.139). Véase ahora, a través de la Tabla 3 , cómo podrían mantenerse precisamente vivas y fortalecerse.
El esfuerzo de la presente investigación ha consistido en comprender la manera como las anteriores propuestas organizativas de hecho pueden determinar un orden, un modo de actuar y de pensar para los miembros de una sociedad. Ha consistido en evidenciar la manera como los líderes hacen uso de las mismas fuentes de legitimación como apelar a la defensa de los Derechos Humanos, a la Constitución de 1991 y a los conceptos de democracia y desarrollo, entre otros. Esto significa que existen unas armas en común, que pueden servir a distintos propósitos según la interpretación de estas fuentes que cada uno de los líderes proponga y de la posibilidad de establecerla como verdadera para un sector de interés o incluso toda la sociedad.

Tabla 3. Tipos de poder observables en cada una de las propuestas organizativas.

\begin{tabular}{|l|}
\hline \multicolumn{1}{|c|}{ PODER REPRESENTATIVO } \\
\hline Consiste en una agrupación humana distinta a las otras, a las \\
cuales intenta suplantar en el ejercicio político y democrático, \\
adquiriendo para sí, como consecuencia, la autonomía que \\
en principio debían conservar la otras agrupaciones humanas \\
representadas para su propia superación. \\
Sólo encuentra posibilidades de desarrollo en la representa- \\
ción, implantando jerarquías, creando relaciones de depen- \\
dencia, promoviendo la pasividad entre los ciudadanos y afir- \\
mando roles sociales específicos.
\end{tabular}

Fuente: Elaboración propia.

\section{DISCUSIÓN}

Como se puede observar, se han encontrado categorías comunes que sirvieron de puente comparativo para determinar la afiliación a una interpretación común, o bien, para establecer diferencias insalvables entre los distintos discursos. Tres conceptos, para comenzar, son los más visibles: Democracia, partidismo y representación. Sea a favor o en contra, estos tres conceptos aparecen claramente en la mayoría de discursos.

\section{Democracia, partidismo y representación}

Por un lado, se encuentran las propuestas que perpetúan el sistema democrático de partidos. Dentro de las distintas definiciones de Ramírez (2009), la siguiente recupera el rasgo en el cual se desea hacer énfasis:

Los sistemas de partidos "configuran el punto de intersección donde convergen todas las fuerzas políticas; 
todo lo que es de importancia política encuentra su lugar dentro de los partidos y en las relaciones entre ellos (Lipson, 1969, citado por Nohlen, 2004). De acuerdo con lo anterior, puede señalarse que el sistema de partidos constituye un elemento vital del sistema político y por consiguiente, de un modelo de Estado, ya que mediante los comicios electorales, sirve de intermediario entre la sociedad y el régimen político (Alcántara, 2001, citado en Ramírez, 2009).

De este modo se recalca en al menos uno de los más importantes objetivos de un sistema de partidos: la participación democrática se debe dar sólo a través de partidos políticos representativos, pues los únicos canales de participación se encuentran cooptados por éstos y no se pueden promover, no existen o no se permite el surgimiento de terceras fuerzas.

De este modo se observa el surgimiento de una democracia donde se espera que un representante en una curul pueda lograr direccionar recursos en beneficio de un sector de la población, sin que importe mucho su afiliación partidista. Este cambio de proyecto político da lugar igualmente a un cambio en las relaciones clientelares: Ya no se basan en una situación simbólica aceptada de legitimidad, donde el cliente (elector) debe lealtad al patrón (político); ahora es el cliente el que adquiere libertad para repensar las propuestas de los líderes, haciendo de su relación una transacción donde no existen intercambios simbólicos de legitimidad o lealtad sino el intercambio conveniente de un favor o de un recurso y de un voto que otorga poder a quien favorece y se lo resta a quien lo da (Corrochano, 2002; Leal, 2010; Leal \& Dávila, 1990). No obstante, la libertad adquirida sigue siendo cuestionable, pues los términos de esa nueva relación y de esa nueva libertad política los siguen dictando los partidos políticos, pues de ningún modo se le permite o se le invita al ciudadano a tener una relación directa con las instituciones estatales, como se pudo observar en los discursos de los líderes partidistas. El tipo de relaciones promovidas sigue siendo entre los ciudadanos y los partidos, no entre los ciudadanos y las instituciones estatales o entre los mismos ciudadanos.

A este nivel, se puede sentar una tesis sobre la real participación de la ciudadanía en un sistema de partidos, tal como el planteado por los líderes locales consultados en el año 2010 en San Gil. Si bien, el clientelismo comúnmente sólo es entendido como la transacción de un favor o dinero, a cambio de un voto el cual otorga poder y prestigio a su destinatario, a través de la presente investigación se puede sostener que, con el sólo hecho de que un representante partidista elegido sea quien otorga asistencialmente a una población un beneficio, se puede hablar de clientelismo. Esto significa que todo sistema de partidos es necesariamente un sistema clientelista. Los sistemas de partidos suponen, así, necesariamente dos cosas: la desviación de la ciudadanía de las vías de participación directa y la pérdida de la posibilidad del autogobierno, dado que es un político de profesión o un notable quien representa a la población ante el Estado, y no los miembro de la misma en calidad de ciudadanos sin curul y políticamente activos. Por ello, se comparte plenamente la sentencia de Mouffe (1995), para quien una democracia representativa consiste en la toma del poder de un sector de la sociedad que convence a otro sector de que la búsqueda de los intereses de este primer sector beneficiará a los demás. En otras palabras, un sector político profesional con intereses particulares convence a los demás sectores de que son ellos quienes deben mantenerse en el poder por el bien de todos.

Pero, véase en la práctica un rasgo que poco es tomado en cuenta por los estudios consultados al respecto. Allí, los fenómenos del clientelismo y de la representatividad son entendidos exactamente al contrario. El caso más claro se encuentra en los discursos de Honorio Galvis, Didier Tavera, Jaime Durán, Mario Suárez y Hugo Aguilar, quie- 
nes piden literalmente el favor a los ciudadanos de apoyarlos en las urnas. De este modo hacen ver a los ciudadanos como patrones con capacidad para hacer favores políticos, y ellos, los representantes partidistas, aparecen como clientesmártires de los ciudadanos. "Y hoy veinte años después venimos con los diputados, venimos con Mario y con Tito, a pedirles a ustedes el favor que nos acompañen en esta decisión que hemos tomado de seguirlos representando", dice Jaime Durán. Ni siquiera es una posición de igualdad la que tratan de describir, sino de sometimiento a la voluntad de los ciudadanos votantes. Parecen ser los ciudadanos quienes tienen el poder de dictar los términos de una transacción clientelar y de dar la oportunidad a uno o a otro no de gobernar, sino de representar la voluntad de los ciudadanos. Y para mitigar la malinterpretación a la que puede dar lugar el concepto de representación, intentan legitimar esta situación apelando a su origen, a su lugar de crianza, un barrio, al lado de unos personajes típicos populares de estrato bajo, sus padres, en un municipio algo remoto del que provienen. De modo que se presentan como uno más de la ciudadanía necesitada, sin dejar de reconocer su afiliación a un partido presentado como una gran red que se despliega desde lo regional a lo central para captar recursos en beneficio de la población local.

La verdadera fuente de poder del representante, como ellos mismos lo hacen saber, está en hacer parte de una efectiva red partidista y clientelar de gestión de recursos que se despliega de lo nacional a lo regional y local. Por ello, a pesar de la crítica que comúnmente se hace a la definición más básica del término "clientelismo político", que ubica la discusión acerca de lo propio de esta práctica en el momento del intercambio del bien o servicio y el voto o respaldo, entre el intermediario y el cliente; tampoco puede ubicarse el análisis únicamente en el "entramado de redes y representaciones culturales construidas diariamente entre políticos y clientes" o en la reconstrucción de la "perspectiva de los clientes" (Auyero, 2008, p.30). Esta propuesta es impor- tante, pero no agota las perspectivas de investigación sobre dicho fenómeno. Lo que se ha encontrado en este trabajo a través del análisis del discurso de los líderes locales, es que la red clientelar involucra toda una estructura partidista que debe desplegarse, para su perfecto funcionamiento, desde un poder central proveedor, pasando por una gran cantidad de figuras con poder, hasta quienes tienen que afrontar directamente los beneficiarios o clientes.

Pero el representante no sólo parece afirmar el sistema democrático en su discurso. En el lenguaje de Nietzsche se puede sostener que los candidatos se presentan como el ideal de ciudadanía, como síntesis entre Estado y sociedad, lo universal y lo particular, lo transcendental y lo efímero, lo divino y lo terrenal. Síntesis que tiene lugar sólo a través de un mecanismo: un partido político, medio para ingresar en un campo general de poder permanente llamado Estado. Es el partido el que da lugar a esa evolución o mutación por la cual debe pasar el ciudadano para hacer del Estado un sistema democrático. Los candidatos se convierten de esta manera en hombres superiores que han alcanzado el más alto propósito del ideal democrático. Hombres superiores que no pueden dejar de parecer hombres humildes por su origen, y que tienen el deber delegado de abogar ante el Estado por los demás hombres humildes. De este modo se puede entender por qué en sus discursos dan la sensación de hacerlo todo: Dicen a la ciudadanía cuáles son los problemas, las soluciones, los criterios para respaldar a un candidato y no a otro. Por ello, al parecer los ciudadanos no deben pensar en absoluto, únicamente encaminarse a las urnas, porque los candidatos ya lo han hecho todo por ellos, hasta el ejercicio de meditar las alternativas. De este modo, es lícito afirma de nuevo que las épocas de campaña no son un espacio de participación, observación y análisis de propuestas, sino el medio litúrgico a través del cual se afirman y renuevan unos roles sociales. No es tanto una época de esperanza o de cambio, como de consolidación de una estructura social, donde aquellos hombres 
superiores afirman su superioridad y los ciudadanos se afirman en su pasividad, en su situación de dependencia.

\section{Movimientos sociales, autonomía ciudadana y democracia directa}

Por otra parte, las propuestas del profesor Miguel Fajardo, el maestro Manuel Sánchez y Fernando Tibaduiza, contrastan radicalmente con los objetivos de los partidos políticos que protegen el sistema de partidos profesionales. El asistencialismo de un Estado de bienestar, la representación de unos partidos políticos, el clientelismo resultante de estas dos situaciones, el establecimiento de la historia de un sólo sector social para todos los demás sectores, la negación de las memorias singulares y de los riesgos de una sociedad industrial, todo ello encuentra su contrapeso en la autonomía económica y solidaria, la constitución de movimientos sociales, el surgimiento de liderazgos sociales, el uso de canales alternativos de participación ciudadana directa y el reconocimiento de la diversidad cultural e histórica.

La reivindicación política que promueve Miguel Fajardo acoge todos los sectores sociales: desplazados, campesinos, actores armados, mujeres y, en general, todos aquellos a quienes no se ha reconocido legalmente su oportunidad de politizar su vida, de escogerla o de contarla, con el ánimo de respaldar la diversidad cultural en Colombia

Al esfuerzo de que cada uno pueda escribir su "propia biografía" (Beck, 1997) también se ha unido el profesor Manuel Sánchez, quien no solo toma en cuenta aquellos que están de algún modo siendo registrados por la historia monumental nacional o desarrollando algún tipo de relación sociales y económica alternativa, sino aquellos que parecen vivir abstraídos de esa realidad: Drogadictos, homosexuales, niños, jóvenes, niños campesinos. Incluso toma en cuenta sectores que no hacen parte de la sociedad civil: Policías y militares. El ejercicio de Fajardo de politizar la vida cotidiana es complementado por el ejercicio de hacer indiscernible en algún punto las fronteras entre lo social y las instituciones públicas, pero también entre lo social o la vida cotidiana y su otra dimensión cuestionable: los excluidos por cuestiones morales, no políticas.

Los derechos por la diferencia, a la oportunidad de tener una vida propia sin ataduras ideológicas ni clientelistas o intermediarias, a un sustento económico no asistencialista ni capitalista, basado en la solidaridad, al reconocimiento de una historia propia y a la capacidad de hacer historia, son los instrumentos a partir de los cuales Miguel Fajardo y Fernando Tibaduiza intentan interpretar e implementar lo acordado en la Constitución de 1991, la cual ordena crear mecanismos de participación social directa y democratizar los medios de difusión (Ramírez, 2009).

Un concepto recuperado de los griegos por el filósofo Carlos Maldonado (2007), reúne y hace ver como una sola las propuestas política y económica de Fajardo y Tibaduiza, por un lado, y la del maestro de Bellas Artes Manuel Sánchez. Este es el de politeia, el cual implica, por una parte, la unión de los miembros de una sociedad, con el objeto de discutir temas relacionados con circunstancias que acontecen a la misma comunidad para buscar soluciones de manera autónoma, tal y como se puede apreciar en las actividades y objetivos planteados por la Asociación de Organizaciones Campesinas y Populares de Colombia, EL COMÚN (Red Nacional de Democracia y Paz - RNDP, 2012), o la Emisora Comunitaria La Cometa (Sanmiguel, 2010). Desde esta perspectiva, la política ya no se definiría más desde temas como gobernabilidad o institucionalidad, que ponen el punto de partida en el Estado y, en últimas, en la supervivencia de éste por encima de la de sus integrantes.

Por el contrario, la política entendida como politeia pone el acento en la sociedad civil y sus problemas, tales como "la cohesión social, el cuidado del medio ambiente, el respeto por los derechos humanos, la calidad y la dignidad de 
la vida, el tipo de conocimiento que se produce, circula, se distribuye y se acumula en la sociedad" (Maldonado, 2007, p.99). Por otra parte, politeia también concibe "la política en términos de vida" (Maldonado, 2007, p.100), como lo desearía el maestro Manuel Sánchez. Si en una sociedad tienen lugar distintas formas de pensar y de vivir, y depende de la misma sociedad que ello suceda, esto implica que el ejercicio político está ofreciendo verdaderas posibilidades de desarrollo a estas formas de vida (ciudadanía, medio ambiente) y no a una sola (el Estado). Ahora bien, Maldonado (2007) entiende la vida desde las ciencias de la complejidad, y desde allí ésta consiste en un triple fundamento: "diversidad genética, natural o biológica y cultural” (p.107). Y la diversidad sólo es posible si cada uno se apropia y defiende su forma de pensar y de vivir- Así, la vida implica acción y autonomía. La política pensada desde lo conveniente para el Estado y los partidos políticos, consiste en la representación, entendida como la delegación de "compromisos, de decisiones, de acciones, de responsabilidades" (Maldonado, 2007, p. 109). Y ésta no parece ser más que la renuncia a la posibilidad de desarrollo autónomo de todas las demás formas de vida.

Lo anterior ha sido parte de la discusión que ha direccionado la presente investigación, cuya motivación ha sido aportar datos relevantes en busca de una explicación al desencuentro entre, por una parte, objetivos democráticos de igualdad social, política y económica $y$, por otra parte, un sistema partidista y representativo que al parecer se convierte en obstáculo para el logro de dichos objetivos. Esto significa que el esfuerzo no sólo ha consistido en demostrar nuevamente esta tesis, sino en comprender la manera como las propuestas anteriormente descritas pueden tener de hecho cabida en la sociedad a partir del uso de la palabra y de lo que ella puede brindar como apoyo a otros mecanismos que van más allá de lo que una campaña política o un discurso pueden lograr. Por ello, es necesario rescatar uno de los más claros hallazgos de la anterior investigación y hacer una invitación. Éste apunta a la red clientelar, la cual según los mismos líderes partidistas, debe desplegarse desde el poder central hasta la situación de intercambio con los llamados "clientes". Afirmar que dicha red está conformada también por actores, que allí tienen lugar unas prácticas, unas formas organizacionales, que buscan mantenerse unos valores, unos objetivos, unas jerarquías, unos vínculos y unos tipos específicos de relaciones, implica hacer una abierta oferta a los estudios en antropología, de incursionar en un campo por completo determinante, pues supone toda una forma de vida y de pensamiento dedicada a administrar los recursos públicos y a definir, de este modo, las oportunidades y formas de desarrollos de las sociedades que toman a su cargo.

\section{REFERENCIAS BIBLIOGRÁFICAS}

Alcaldía de San Gil. (2008). Plan de Desarrollo Municipal 2008-2011, Tenemos Futuro. San Gil: Alcaldía de San Gil.

Apud, I. (2013). Repensar el método etnográfico. Hacia una etnografía multitécnica, reflexiva y abierta al diálogo interdisciplinario. Antípoda: revista de antropología y arqueología (16), 213-235.

Auyero, J. (2008). Repensando el tropo del clientelismo político. Villa libre, cuadernos de estudios sociales urbanos (3), 5-35.

Bauman, Z. (2005). Amor líquido. Acerca de la fragilidad de los vínculos humanos. Madrid: Fondo de Cultura Económica.

Beck, U. (1997). La reinvención de la política: Hacia una teoría de la modernización reflexiva. En Beck, Giddens y Lash (Ed.), Modernidad reflexiva, politica, tradición y estética en el orden social moderno (pp. 13-72). Madrid: Alianza Editorial.

Benjamin, W. (1998). Para una crítica de la violencia. Iluminaciones $I V$. España: Taurus.

Botero, R. (2005). La argumentación política como ejercicio del poder. En L. Ramirez \& G. Acosta (Comp.), Estudios del Discurso en Colombia (pp. 139-154). Colombia: Universidad de Medellín. 
Clastres, P. (1978). La Sociedad Contra el Estado. Barcelona, España: Monte Avila Editores, C.A. Corrochano, D. (2002). El clientelismo posmodernista. Perfiles Latinoamericanos, (20), 131-155.

Deleuze, G. \& Guattari, F. (1994). Mil mesetas. Capitalismo y esquizofrenia. Barcelona: Pretextos.

Dijk, T. (2004). Discurso y dominación. Grandes Conferencias en la Facultad de Ciencias Humanas UNAL (4), 1-28.

Dijk, T. (1996). Estructuras y funciones del discurso: una introducción interdisciplinaria a la lingüística del texto y a los estudios del discurso. México: Siglo Veintiuno Editores.

Foucault, M. (2001) [1983]. El sujeto y el poder. Post-scriptum. En H. Dreyfus \& P. Rabinow (ed.), Michel Foucault: más allá del estructuralismo y la hermenéutica (pp. 241-259). Buenos Aires: Editorial Nueva Visión.

Gobernación de Santander. (2008). PDD - Plan de Desarrollo Departamental 2008-2011. Recuperado de

https://www.uis.edu.co/webUIS/es/investigacionExtension/documentos/docInteres/pddSantanderIncluyente.pdf

Guber, R. (2001). La etnografia: método, campo y reflexividad. Bogotá: Grupo Editorial Norma. Hendricks, J. (1996). Poder y conocimiento: discurso y transformación ideológica entre los Shuar. En F. Santos Granero. Globalización y cambio en la Amazonía indígena (pp. 131182). Quito, Ecuador: Ediciones Abya-Yala.

Jiménez, S. (2005). La dimensión retórica y el discurso de Álvaro Uribe Vélez sobre el conflicto armado en Colombia. En L. Ramírez \& G. Acosta (Comp.), Estudios del Discurso en Colombia (pp. 155-172). Medellín, Colombia: Universidad de Medellín.

Leal, F. (2010). Bipartidismo y configuración del clientelismo en Colombia (Segunda parte). Razón Pública. Recuperado de http://www. razonpublica.com/index.php?option=com_co ntent\&view=article\&id=1595:bipartidismo-yconfiguracion-del-clientelismo-en-colombiasegunda-parte\&catid=19:politica-y-gobierno\&Itemid $=27$
Leal, F. \& Dávila, A. (1990). El clientelismo: el sistema político y su expresión regional, Bogotá, IEPRI - Universidad Nacional: Tercer Mundo Editores.

Lins, G. (2007). Poder, redes e ideología en el campo del desarrollo. Tabula Rasa (6), 173-193. Maldonado, C. (2007). Política y sistemas no lineales: la biopolítica. En V. Orbegozo (Coord.), Dilemas de la política (pp. 91-142). Bogotá: Universidad Externado de Colombia.

Mouffe, C. (1995). La democracia radical ¿Moderna o posmoderna? En P. Santana (Comp.), Las incertidumbres de la democracia (pp. 287-303). Bogotá: Ediciones Foro Nacional por Colombia.

Nietzsche, F. (2002). La Genealogía de la moral. Madrid: Alianza editorial.

Ramírez, G. (2009). Fragmentación partidista en Colombia. Estudios en Derecho y Gobierno 2 (1), 27-50.

Ramírez, L. (2005). Texto y discurso. En L. Ramírez y G. Acosta (Comp.), Estudios del Discurso en Colombia (pp. 93-116). Medellín, Colombia: Universidad de Medellín.

Red Nacional de Democracia y Paz, RNDP. (2012). Asociación de Organizaciones Campesinas y Populares de Colombia - El Común. Recuperado de http://www.rndp.org. co/node/96

Richard, E. (2009). Álvaro Uribe: la comunicación por la imagen. Principios de marketing político. Revista Opera, (8), 73-100.

Rivoir, A. L. (1999). Redes sociales: ¿Instrumento metodológico o categoría sociológica? Revista Ciencias Sociales, (15), 49-58.

Rocher, G. (1990). Introducción a la sociología general. Barcelona: Herder.

Rodríguez, L., Padilla, A., Rodríguez, L. S. \& Díaz, F. (2010). Análisis de la justicia restaurativa para atender casos de violencia intrafamiliar en el Centro de Atención Integral a Víctimas de Violencia Intrafamiliar (CAVIF) de la Fiscalía General de la Nación, Colombia. Diversitas: Perspectivas en Psicología, 6 (2), 355-373. 
Salcedo, A. \& Zeiderman, A. (2008). Sanmiguel,E.(2010).Misiónyvisión.Lacometa:emiAntropología y ciudad: hacia un análisis crítico sora comunitaria de San Gil. Recuperado de http:// e histórico. Antípoda: revista de antropología y arqueología, (7), 63-97. www.lacometa.com.co/index.php?option=com_co ntent\&view=article\&id=120\&Itemid=194 